\title{
Transcription of ENOD8 in Medicago truncatula Nodules Directs ENOD8 Esterase to Developing and Mature Symbiosomes
}

\author{
Laurent Coque, ${ }^{1}$ Purnima Neogi, ${ }^{1}$ Catalina Pislariu, ${ }^{1}$ Kimberly A. Wilson, ${ }^{1}$ Christina Catalano, ${ }^{2}$ \\ Madhavi Avadhani, ${ }^{2}$ D. Janine Sherrier, ${ }^{2}$ and Rebecca Dickstein ${ }^{1}$ \\ ${ }^{1}$ University of North Texas, Department of Biological Sciences, Chestnut and Avenue C, Denton 76203-5220, U.S.A.; \\ ${ }^{2}$ Department of Plant and Soil Sciences and Delaware Biotechnology Institute, University of Delaware, Newark 19711, U.S.A.
}

Submitted 25 October 2007. Accepted 5 December 2007.

In Medicago truncatula nodules, the soil bacterium Sinorhizobium meliloti reduces atmospheric dinitrogen into nitrogenous compounds that the legume uses for its own growth. In nitrogen-fixing nodules, each infected cell contains symbiosomes, which include the rhizobial cell, the symbiosome membrane surrounding it, and the matrix between the bacterium and the symbiosome membrane, termed the symbiosome space. Here, we describe the localization of ENOD8, a nodule-specific esterase. The onset of ENOD8 expression occurs at 4 to 5 days postinoculation, before the genes that support the nitrogen fixation capabilities of the nodule. Expression of an ENOD8 promotergusA fusion in nodulated hairy roots of composite transformed M. truncatula plants indicated that ENOD8 is expressed from the proximal end of interzone II to III to the proximal end of the nodules. Confocal immunomicroscopy using an ENOD8-specific antibody showed that the ENOD8 protein was detected in the same zones. ENOD8 protein was localized in the symbiosome membrane or symbiosome space around the bacteroids in the infected nodule cells. Immunoblot analysis of fractionated symbiosomes strongly suggested that ENOD8 protein was found in the symbiosome membrane and symbiosome space, but not in the bacteroid. Determining the localization of ENOD8 protein in the symbiosome is a first step in understanding its role in symbiosome membrane and space during nodule formation and function.

Nitrogen-fixing nodules form on the roots of legumes as the culmination of a successful interaction between the plant and soil bacteria called rhizobia. Nodule development is a complex process that involves differentiation of both symbiotic partners (Brewin 2004; Gage 2004; Hirsch 1992; Jones et al. 2007). After

Current address of L. Coque: Department of Psychiatry, University of Texas Southwestern Medical Center, Dallas 75390-9070, U.S.A.

Current address of C. Pislariu: The Samuel Roberts Noble Foundation, Ardmore, OK 73401, U.S.A.

Current address of K. A. Wilson: Departments of Pediatrics and Biochemistry, University of Texas Southwestern Medical School, Dallas, TX 75390-9063, U.S.A.

Corresponding author: Rebecca Dickstein;

E-mail: beccad@unt.edu; Fax +1.940.565.3821.

* The $\boldsymbol{e}$-Xtra logo stands for "electronic extra" and indicates that a supplemental figure is published online. attaching to root hairs, reorienting root hair cell wall growth, and forming a bacterial colony within a tightly curled root hair, rhizobia enter plant roots through plant-derived infection threads that traverse several cell layers. Ultimately, the rhizobia are deposited in nodule primordium cells in a process that resembles endocytosis or phagocytosis.

A plasma membrane-derived membrane surrounds each bacterium and results in a new organelle-like compartment in the infected nodule cells termed the symbiosome. Within symbiosomes, coordinated division of rhizobia and the symbiosome membrane occurs. Eventually, rhizobial division ceases and rhizobia differentiate into bacteroids, a form recognized as being capable of nitrogen fixation (Vasse et al. 1990). The matrix that surrounds the bacteroid is called the symbiosome space. In some literature, the symbiosome membrane and the symbiosome space are termed the peribacteroid membrane and peribacteroid space, respectively (Hirsch 1992). Both the symbiosome space and the symbiosome membrane become specialized during nodule development concomitantly with bacteroid differentiation, and these changes eventually enable nitrogen fixation and transport.

In mature indeterminate nodules, such as the type formed by Medicago truncatula, nodule invasion occurs immediately adjacent to the nodule meristem, in zone II (Vasse et al. 1990). Rhizobial division and differentiation occur within zone II. Starch accumulation marks the interzone II to III, proximal to zone II, where the final stages of bacteroid differentiation occur. Nitrogen fixation occurs in zone III. In older nodules, a senescent zone IV also occurs (Hirsch 1992).

The symbiosome membrane serves as a physical barrier and a mediator of metabolite exchange between the bacteroid and the plant host cell cytosol (Udvardi and Day 1997). In nitrogenfixing nodule cells, the symbiosome membrane resembles both the plasma membrane and the vacuole membrane with respect to its substituent proteins (Brewin 1991; Mylona et al. 1995). Previous studies have focused on the biochemical composition of the symbiosome membrane and how it differs from other cellular membranes, how it changes during symbiosome and bacteroid maturation, and functions during nodule development and nitrogen fixation (Catalano et al. 2004, 2007; Panter et al. 2000; Wienkoop and Saalbach 2003).

Proteomic analysis indicates that approximately 200 proteins exist in the symbiosome space in M. truncatula (Catalano et al. 2004) and in pea (Saalbach et al. 2002). Immunolocalization studies have shown that a lectin protein (Dahiya et al. 1997; Kardailsky et al. 1996) and a cysteine protease are in the symbiosome space (Vincent and Brewin 2000) in addition to sev- 
eral members of a calcium-binding protein family (Liu et al. 2006). However, the functional significance of many of the proteins in the symbiosome space is largely unknown.

In this report, we describe the localization of ENOD8. In M. truncatula, ENOD8 is a member of a duplicated gene family of which only ENOD 8 is highly active in root nodules (Dickstein et al. 2002). ENOD8 belongs to the GDSL family encoding hydrolytic enzymes (Akoh et al. 2004; Upton and Buckley 1995). This gene family, consisting of plant and bacterial genes, encodes hydrolytic proteins, some of which have esterase, lipase, or carbohydrate hydrolase activity. Of the GDSL plant enzymes that have been biochemically characterized, lanatoside $15^{\prime}-O$-acetylesterase (LAE) from Digitalis lanata is a close homolog to ENOD8, with $44 \%$ sequence identity at the amino acid level (Kandzia et al. 1998). LAE deacetylates the substrate lanatoside A, an acetylated glycosylated steroid, to purpureaglycoside A in cardenolide metabolism. Another close homolog of ENOD8 (47\% identical) encodes an exopolygalacturonase from Daucus carota, carrot (Tanaka et al. 2002). The exopolygalacturonase is 97\% identical to iEP4 (Bertinetti and Ugalde 1996) and EP4, found extracellularly (van Engelen et al. 1995). Purified M. sativa ENOD8 proteins have esterase activity that is more active on shorter-chain esters than on longer-chain esters (Pringle and Dickstein 2004). ENOD8 protein was shown to be completely soluble in aqueous solutions (Pringle and Dickstein 2004). Curiously, ENOD8 protein also was identified in purified symbiosome membrane fractions (Catalano et al. 2004). To date, however, there has been no comprehensive study of the distribution of ENOD8 protein localization.

Here, we report on the spatial localization of a $\mathrm{pENOD8-}$ gusA transgene in $M$. truncatula nodules. We also report on the localization of the ENOD8 protein product to infected cells of this same region of nitrogen-fixing nodules. Within the nodules, ENOD8 protein localizes to the symbiosome space and symbiosome membrane. These results provide intriguing insights into the role of potential esterase activity of ENOD8 protein in nodule formation and function.

\section{RESULTS}

\section{Localization of ENOD8 gene expression.}

To determine the spatial localization of ENOD8-regulated transcription, a translational fusion of the $2.98-\mathrm{kb}$ sequence upstream of the highly active ENOD8.1 gene and the reporter gene gusA was constructed (pMtENOD8-gusA). This was used to transform $M$. truncatula A17 roots in a hairy root system (Boisson-Dernier et al. 2001). Control plants were transformed with Agrobacterium rhizogenes carrying the pMtENOD11-gusA fusion (Boisson-Dernier et al. 2001). Composite plants with transformed roots were placed in aeroponics chambers and inoculated with Sinorhizobium meliloti to induce nodulation. Three weeks after inoculation, nodulated root systems were harvested and stained with 5-bromo-4-chloro-3-indolyl- $\beta$-Dglucuronide, cyclohexylammonium salt (X-Gluc) (Fig 1). pMtENOD8-gusA expression was found primarily in nodule zone III. Occasionally, expression also was detected in the proximal end of interzone II to III (IZ II-III). The zones were identified by staining nodules with iodine to identify the starch that accumulates in IZ II-III (not shown). No expression was seen in the meristem or in the uninfected nodule periphery. Expression of pMtENOD11-gusA in control nodules showed XGluc staining at the distal end of the nodule, similar to published results (not shown) (Boisson-Dernier et al. 2001; Journet et al. 2001). The nodules formed on transgenic hairy roots with both the pMtENOD8-gusA transgene construct and control constructs were smaller than those found on untransformed tissue. There was some variability of staining from nodule to nodule; most of the nodules examined came from independent transformation events. The nodule shown in Figure 1 represents the staining pattern found in most $\mathrm{pMt} E N O D 8$-gusA-transformed nodules.

\section{Localization of ENOD8 protein at the tissue level.}

An ENOD8 antiserum was used to localize ENOD8 protein in fixed nodule sections. This antibody that was raised against the oligopeptide CKNPSTRITWDGTHYTEAA was reported previously (Dickstein et al. 2002; Pringle and Dickstein 2004). This sequence corresponds to amino acids 336 to 354 of the M. sativa ENOD8 putative polypeptide sequence (GenBank accession AAB41547) and an $89 \%$ identical sequence in $M$. truncatula's predicted ENOD8 protein (GenBank accession AAC26810). This antiserum has high specificity for ENOD8 protein from both $M$. sativa and $M$. truncatula (Dickstein et al. 2002). In conditions tested previously, the antiserum was not an effective ENOD8 protein localization tool (Pringle and Dickstein 2004). After trial and error, a protocol was found that recovers antigen signal loss during fixation (see Methods). Additionally, and in confirmation of staining patterns obtained, we raised another ENOD8 antiserum to a recombinant maltose-binding protein (MBP)-ENOD8 fusion protein and used it instead of the ENOD8 oligopeptide antiserum in additional immunolocalization experiments not reported here. In every tested case, identical localization patterns were observed when the MBP-ENOD8 fusion protein antiserum were used (data not shown), instead of the ENOD8 oligopeptide antiserum.

ENOD8 antibodies were purified from the ENOD8 oligopeptide antiserum by immunoaffinity chromatography and were used in immunolocalization experiments. To assess the utility of the ENOD8 antibodies in localization, they were immunodepleted with ENOD8 oligopeptide. The ENOD8 antibodies specifically label infected cells in the interior of the nodule, but also apparently have nonspecific binding in the nodule periphery (Supplemental Figure 1). The specific staining disappears in ENOD8 antibodies preincubated with ENOD8 oligopeptide, whereas the nonspecific staining persists. Preimmune antisera did not label nodules.

To determine which tissues within $M$. truncatula nodules ENOD8 protein localizes, nodule sections were treated with immunopurified ENOD8 antibodies followed by Cy5-labeled secondary antibodies and then observed by confocal microscopy (Fig. 2A). Sections serial to the immunolabeled section were stained with iodine to localize IZ II-III and observed in the light microscope (Fig. 2B). Comparison of Figure 2A and $\mathrm{B}$ show that ENOD8 protein is found in IZ II-III and in zone III, the nitrogen-fixing zone. The protein distribution is similar to the pattern of expression found for pMtENOD8-gusA transgene expression. Except for the nonspecific nodule periphery staining noted above, ENOD8 protein staining appears to be confined to the infected cells, because the cells staining for expression are large and the staining pattern is ring shaped, consistent with infected cells. ENOD8 protein staining is more intense at the proximal end of the nodule (Fig. 2A); this pattern is consistent in all nodule sections observed.

\section{Intracellular localization of ENOD8 protein.}

Higher magnification confocal microscopy was used to localize ENOD8 protein at the cellular level. To control for antibody diffusion into the fixed nodule tissue and accessibility of the antiserum to the nodule cells, a commercially available control antibody to histone $\mathrm{H} 1$ was used. The assumption is that the diffusion of the histone $\mathrm{H} 1$ antibodies and the ENOD8 antibodies should be similar. TRITC-conjugated secondary antiserum was used to detect the histone $\mathrm{H} 1$ antibody (Fig. 3, blue) and Cy5-conjugated secondary antibody was used to detect the 


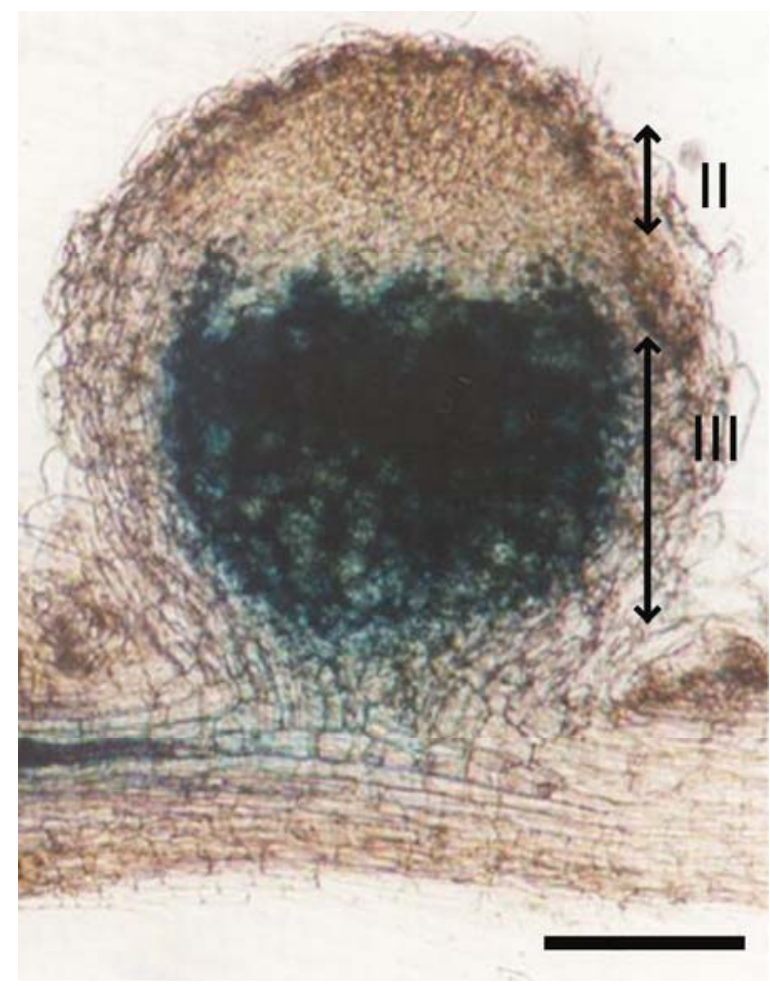

Fig. 1. Expression of pMtENOD8-gusA transgene in nodulated hairy root of composite Medicago A17 plants transformed via Agrobacterium rhizogenes. Roots were transformed with pMtENOD8-gusA and subsequently inoculated with Sinorhizobium meliloti in an aeroponic system. At 25 days postinoculation, the roots were fixed, sectioned, and stained with 5-bromo-4-chloro3 -indolyl- $\beta$-D-glucuronide, cyclohexylammonium salt (blue), visualizing the pMtENOD8-gusA expression in the proximal part of the nodule. The double arrows mark the locations of zones II and III. Bar $=0.5 \mathrm{~mm}$.

immunopurified ENOD8 antibody (Fig. 3, red). SYTO13 was used as a counterstain to show the distribution of the rhizobia (Fig. 3, green) (Haynes et al. 2004). No ENOD8 label was detected in uninfected cells (data not shown). In infected cells of IZ II-III and zone III, ENOD8 label was correlated with symbiosomes (Fig 3). No ENOD8 label was detected in infected cells from the infection zone after bacteroid replication and elongation (Fig. 3B). Only cells in IZ II-III and zone III label with ENOD8 antibodies (Fig. 3C). From the merged images in Figure 4C, the left-hand side of the infected cell has symbiosomes that have their long axis almost perpendicular to the focal plane (arrow). In these symbiosomes, the ENOD8 label clearly can be seen to surround the bacteroid label. At higher magnification, ENOD8 antibodies detected ENOD8 protein in areas immediately surrounding the bacteroids, in the symbiosome space or symbiosome membrane (Fig. 4).

We attempted to localize ENOD8 protein using immunoelectron microscopy. However, under the harsh fixation conditions required for electron microscopy (Sherrier et al. 2005), ENOD8 could not be detected with either ENOD8 antiserum.

\section{Immunodetection of ENOD8 protein in fractionated nodules.}

Confocal microscopy does not permit the immunolocalization of ENOD8 protein within the symbiosome. Mass spectrometry has indicated that ENOD8 protein may be a component of the symbiosome membrane (Catalano et al. 2004). In order to further provide the biochemical evidence for localization of ENOD8 in the symbiosome, blots containing total protein from the symbiosome membrane, symbiosome space, and bacteroid fractions were probed with ENOD8 antiserum. Significantly
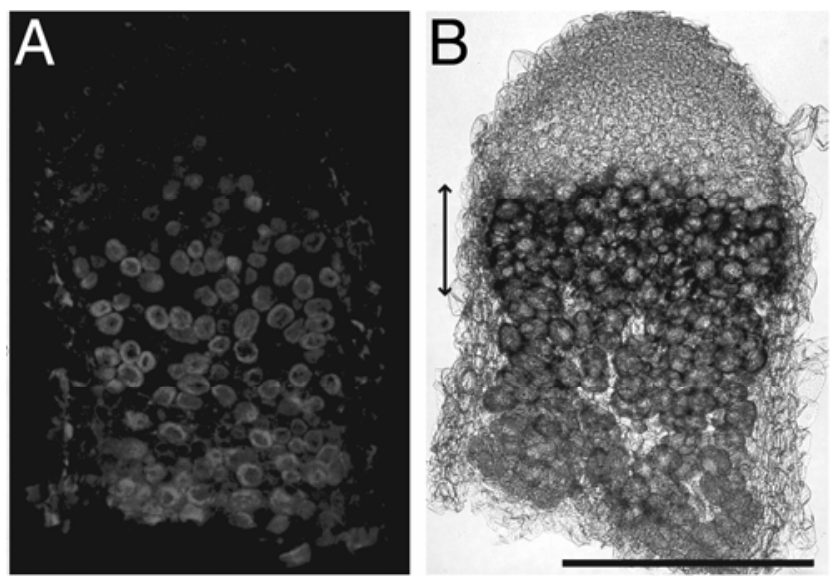

Fig. 2. ENOD8 protein localizes to cells in interzone (IZ) II to III and zone III. A, Nodule section immunostained with immunopurified ENOD8 antibodies imaged by confocal microscopy. Cells that label specifically for ENOD8 have ring structures, indicative of infected cells. B, Section serial to the section in A, stained with iodine to localize the IZ II-III. The double arrow marks IZ II-III. Bar $=1 \mathrm{~mm}$.

higher levels of ENOD8 protein were detected in the symbiosome space relative to the symbiosome membrane (Fig. 5B). Control blots were stained with Ponceau (Fig. 5A) and stained for markers of the symbiosome membrane (Fig. 5C) and bacteroid fractions (Fig. 5D) using nodulin-26 and dinitrogenase reductase antisera, respectively. Ponceau was found to stain the hydrophobic proteins in the symbiosome membrane less effectively than the more soluble proteins in the other fractions (Fig. $5 \mathrm{~A})$. Nodulin-26 was detected as an approximately $32-\mathrm{kDa}$ protein in the symbiosome membrane fraction, consistent with the predicted size of $M$. truncatula nodulin-26. Although nodulin-26 antisera showed significant cross reactions with the proteins in the symbiosome space fractions, no protein corresponding to the size of nodulin-26 was detected in that fraction suggesting the purity of the symbiosome membrane fraction. A $31-\mathrm{kDa} S$. meliloti-specific dinitrogenase reductase was detected in the bacteroid fraction (Fig. 5D). However, a control immunoblot for the symbiosome space fraction could not be performed due to the nonavailability of specific antiserum. Thus, these experiments suggest the localization of ENOD8 protein to the symbiosome space, with a smaller amount localizing to the symbiosome membrane. It also is possible that the ENOD8 protein in the membrane fraction represents a small amount trapped inside sealed vesicles of the symbiosome membrane preparation.

\section{DISCUSSION}

In this study, we report the distribution of pMtENOD8-gusA transgene expression and the ENOD8 protein in symbiotic nodules of $M$. truncatula, providing insight into the role of ENOD8 in nodule development. ENOD8 proteins have esterase activity, more active on methyl esters than on longer-chain esters of model ester substrates (Pringle and Dickstein 2004). Use of a pMtENOD8-gusA transgene in A. rhizogenes-transformed roots of composite Medicago plants shows expression in the parts of the nodule where cells infected with rhizobia inside symbiosomes are found. However, not all developmental stages of symbiosome-containing cells express the pMtENOD8gusA transgene. Expression was not found in zone II, which contains dividing and differentiating rhizobia inside symbiosome membranes (Vasse et al. 1990). Use of an immunopurified antibody that was raised against an ENOD8-specific peptide allowed visualization of the ENOD8 protein inside rhizobiainfected cells at the tissue level and inside symbiosomes at the 

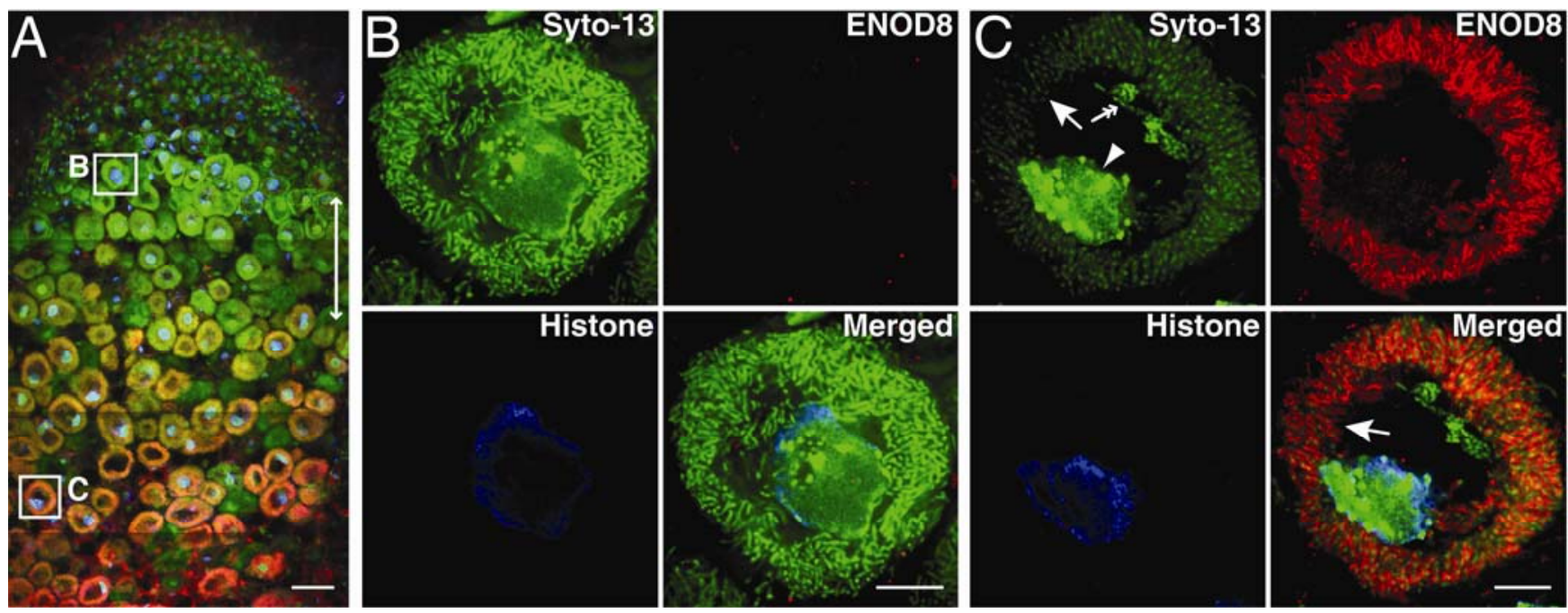

Fig. 3. Distribution of ENOD8 in infected nodule cells. Staining with ENOD8 antisera (red) with histone antisera (blue) as an antibody accessibility control and SYTO13 (green), a soluble nucleic-acid binding dye, shows positions of bacteroids. A, Stained nodule shows positions of individual cells investigated at high magnification in B and C. The double arrow marks interzone (IZ) II to III. Bar $=50 \mu \mathrm{m}$. B, Infected cell from middle of IZ II-III shows elongated bacteroids (green, upper left) and histone staining in nuclei (blue, lower left), but no ENOD8 staining (red, upper right) in merged image (lower right). Bar = $10 \mu \mathrm{m}$. C, Infected cell from nitrogen-fixing zone III. Elongated bacteroids (arrow) and an infection thread remnant (double arrow), and the nucleus (arrowhead) stain with SYTO13 (green, upper left), histone staining in nuclei (blue, lower left), prominent ENOD8 staining (red, upper right) in the merged images (lower left) show that ENOD8 labeling surrounds the bacteroids' staining. At points in the cell where the symbiosomes are almost perpendicular to the confocal plane, the ENOD8 staining (red) can be seen to surround the bacteroid staining (green) (arrow). Bar $=10 \mu \mathrm{m}$.

subcellular level. Previous proteomic experiments to identify proteins found in the symbiosome membrane showed that ENOD8 is found in this membrane (Catalano et al. 2004). In studies reported here, differentially separated nodule fractions probed on Western blots suggest that ENOD8 protein is found in the symbiosome space as well.

This is the first report of a biochemical change in a plant component of symbiosomes as they mature from having newly deposited type 1 bacteroids inside the symbiosome membrane to nitrogen-fixing forms with elongated type 4 bacteroids (Vasse et al. 1990). ENOD8 protein is observed in developing and mature symbiosomes. In symbiosomes at the distal end of zone II, bacteroids already have elongated (Vasse et al. 1990) and ENOD8 is not observed (Figs. 2 and 3B). At the distal end IZ II-III, ENOD8 expression begins, persisting to the nitrogenfixing zone (Fig. 3C).

We previously reported that $E N O D 8$ encoded a protein with a signal sequence and no predicted transmembrane domains (Dickstein et al. 1993, 2002). Based on similarities with homologous proteins that are secreted and associated with the apoplast (Kandzia et al. 1998; van Engelen et al. 1995) and its biochemical property of complete solubility in aqueous solutions, we anticipated that ENOD8 protein also would be secreted and localize to the exterior of the plasma membrane (Pringle and Dickstein 2004). Topologically, the symbiosome is external to the cytosol; thus, the localization of ENOD8 protein to symbiosomes is consistent with previous predictions. Other proteins that localize to symbiosomes also have a signal sequence (Kardailsky et al. 1996; Liu et al. 2006), but no one has yet determined whether consensus amino acid motifs exist which might be recognized by host-targeting machinery to target plant host proteins there. Thus, there is as yet no way to predict that ENOD8 encodes a symbiosome-localized protein.

Most ENOD8 protein was found to localize to the symbiosome space, with a smaller amount localizing to the symbiosome membrane, although it was impossible to rule out a small amount of symbiosome space inside sealed vesicles contaminating the symbiosome membrane fractions. Because of its solubility in aqueous solutions and lack of predicted transmembrane domains, the fraction of ENOD8 protein that is apparently in
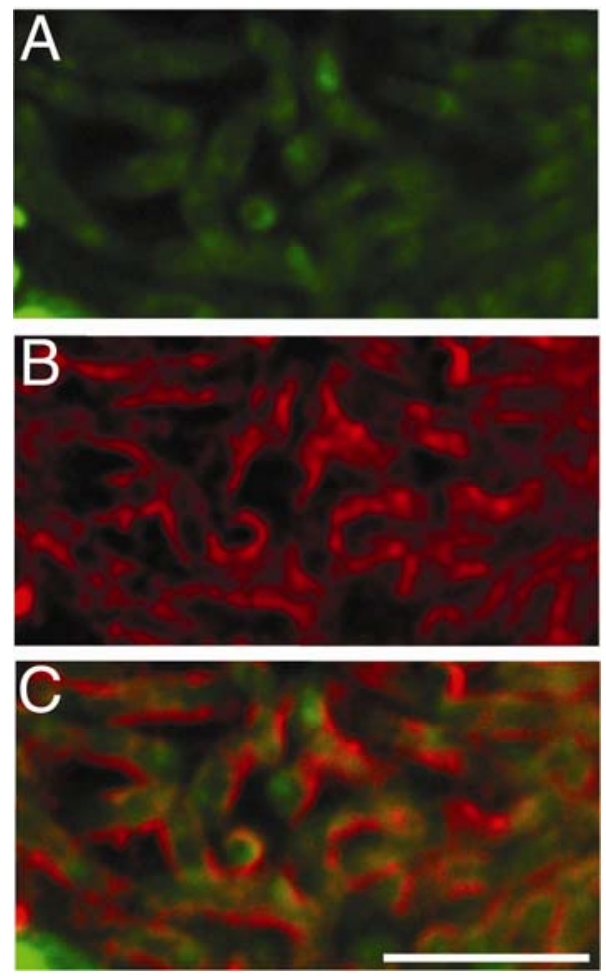

Fig. 4. Immunolocalization of ENOD8 in symbiosomes. High magnification of symbiosome region in an infected cell. A, Staining with SYTO13 visualizes bacteroids. B, Staining with anti-ENOD8 antibodies. C, Merged image shows ENOD8 protein surrounding the bacteroids. Bar $=10 \mu \mathrm{m}$.

the symbiosome membrane is likely a peripheral membrane protein, bound to another symbiosome membrane molecule that is intrinsically attached to the membrane.

Because of its localization, ENOD8 protein may be integral to symbiosome function. ENOD8 protein is a member of the GDSL family of hydrolytic enzymes. In plants, GDSL member proteins are involved in secondary metabolism. Although we previously have shown ENOD8 protein to have esterase activity 
against model substrates, especially shorter ester chains (Pringle and Dickstein 2004), we still do not understand the nature of its true substrates. Because of the previous observation that ENOD8 expression persists after nitrate addition (Dickstein et al. 2002), it is unlikely that ENOD8 protein is required for nitrogen fixation per se. ENOD8 protein has high similarity to LAE and to the exopolygalacturonase EP4 (Bertinetti and Ugalde 1996; Tanaka et al. 2002; van Engelen et al. 1995), both of which act on carbohydrate substrates; thus, we predict that ENOD8 protein's substrate is also an oligo- or polysaccharide. iEP4 was found to be inducible by elicitors (Bertinetti and Ugalde 1996), which raises the possibility that it and its homologs, including ENOD8, have defensive roles. The finding that ENOD8 protein is in the symbiosome space and, possibly, membrane opens the intriguing possibility that ENOD8's substrate could be a surface molecule of bacteroid origin. Could ENOD8's substrate be rhizobially produced Nod factor, exopolysaccharide, or lipopolysaccharide? The latter is known to change during bacteroid development (Kannenberg and Carlson 2001). It is equally possible that ENOD8 acts on a plant symbiosome-targeted substrate that controls bacteroid differentiation, function, or proliferation or an aspect of symbiosome function.

\section{MATERIALS AND METHODS}

\section{Plant growth.}

Wild-type A17 and composite A17 plants with transformed roots were grown in aeroponic chambers as previously described (Veereshlingam et al. 2004), misted in a nitrogen-free nutrient media (Lullien et al. 1987), and inoculated with $S$. meliloti 5 days after germination. Plants were maintained on a regime of $16 \mathrm{~h}$ of light and $8 \mathrm{~h}$ of dark at $22^{\circ} \mathrm{C}$.

\section{ENOD8.1 promoter-gusA fusion construct.}

pRD022 was constructed by cloning the 3.2-kb SphI piece of pCAMBIA2301 into pUC18. This $3.2-\mathrm{kb}$ piece of pCAMBIA2301 contains lacZ $\alpha$, the Cauliflower mosaic virus 35S promoter, and $\beta$-glucuronidase containing the catalase intron.
Six ENOD8 genes have been found to be on the fully sequenced BAC mth1-64n13 (GenBank accession AC139354), of which one, ENOD8.1, has been found to be highly expressed in nodules (Dickstein et al. 2002). ENOD8.1 also is found on the partially sequenced BAC mth1-19n23 that overlaps BAC mth1-64n13. The ENOD8.1 promoter was obtained with flanking $\mathrm{SacI}$ and $\mathrm{NcoI}$ restriction sites by polymerase chain reaction (PCR) from BAC mth1-19n23 by PCR with the following primers: SacI-ENOD8p: 5'-GATCGAGCTCCACC GGACCTATTGACTAGC and ENOD8p-NcoI: 5'-GCATGCC ATGGATTTCATGAAGCAATAAAGGAACC. These primers amplify DNA from nucleotides 7,570 to 10,551 from GenBank accession AF463407 (BAC mth1-19n23) that contains $2.98 \mathrm{~kb}$ of DNA immediately upstream of the translational start codon of ENOD8.1. The 2.98-kb PCR fragment was digested with SacI and NcoI and ligated to similarly digested pRD022, creating a translational fusion between the ENOD8.1 upstream sequence and gusA. The PCR manipulations changed the sequence at the translational start of ENOD8.1 from 5'-TTCATGG to 5'TCCATGG. The resulting plasmid then was digested with SacI and BstEII. The 4.23-kb SacI-BstEII fragment containing the ENOD8.1 promoter fused to gusA subsequently was ligated into pCAMBIA2301, creating pRD027. pRD027 was transformed into A. rhizogenes ARqua1 and used for hairy root transformations (Boisson-Dernier et al. 2001). In addition to nodule staining in the nodule as shown in the results, X-Gluc staining in the root stele also was observed occasionally in roots transformed with $\mathrm{pMtENOD8-gusA}$ transgene and the control transgene, which may be a stress response to hairy root transformation (D. Barker, personal communication).

Nodules containing the pMtENOD8-gusA transgene or $\mathrm{p} M t E N O D 11-$ gusA control transgene were fixed in $4 \%$ (vol/vol) formaldehyde in 0.1 M PIPES buffer, and stained with X-Gluc (Gold Biotechnology, St. Louis) as described (Journet et al. 1994).

\section{MBP-ENOD8 protein fusion construct.}

The nucleotides 100 to 1,158 sequence of the $M$. sativa ENOD8 cDNA (GenBank L18899) was engineered by PCR
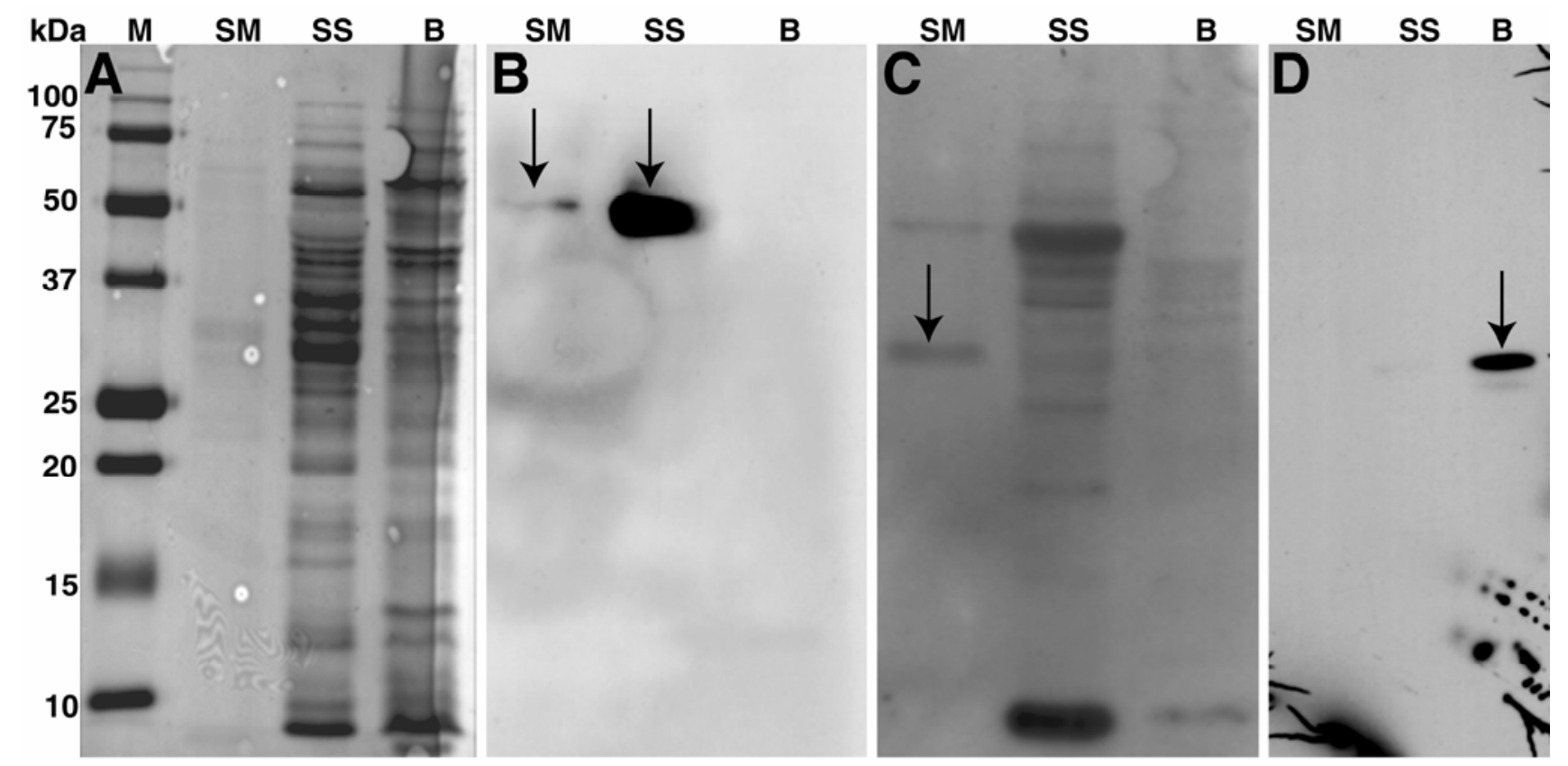

Fig. 5. Immunoblot analysis of ENOD8 protein in Medicago root nodule protein fractions. A, Ponceau-stained blot showing total protein $(50 \mu \mathrm{g} / \mathrm{lane})$ in the symbiosome membrane (SM), symbiosome space (SS), and bacteroid (B) fractions. Blot probed with B, anti-ENOD8; C, anti-nodulin 26, a marker for the symbiosome membrane; and $\mathbf{D}$, anti-dinitrogenase reductase, a marker for the bacteroid fraction. Arrows indicate the relevant chemiluminescent signal in panels B, C, and D. 
with the ForpMAL primer (GCACCCCGGGACACATTG TG ATTTTCCTGCC) to add a SmaI site at the $5^{\prime}$ end of the PCR product and with the RevpMAL primer (GCACGTCGACTCA CTTTCTATAACATGCCATATCTAG) to add a SalI site to the $3^{\prime}$ end of the PCR product. The PCR product was sequentially digested with SmaI, then SalI, ligated into an Xmn1, SalIdigested pMAL-p2X vector (New England Biolabs, Beverly, MA, U.S.A.), and transformed in TOP10 competent cells (Invitrogen, Carlsbad, CA, U.S.A.). Positive colonies were sequenced (Lone Star Labs, Inc., Houston) with custom primers to identify the correct clone.

\section{MBP-ENOD8 protein fusion purification.}

An Escherichia coli strain carrying the MBP-ENOD8 construct was grown at $37^{\circ} \mathrm{C}$ on a shaker in Luria-Bertani media supplemented with streptomycin at $10 \mu \mathrm{g} / \mathrm{ml}$ and ampicillin at $100 \mu \mathrm{g} / \mathrm{ml}$, until absorbance at $600 \mathrm{~nm}$ was 0.5 . Isopropyl- $\beta$-Dthiogalactoside was added to $0.03 \mathrm{mM}$ to induce recombinant expression overnight at room temperature (RT) with shaking. The induced bacterial pellet was recovered by centrifugation and resuspended in column buffer $(20 \mathrm{mM}$ Tris- $\mathrm{HCl}, \mathrm{pH} 7.4$; $200 \mathrm{mM} \mathrm{NaCl}$; and $1 \mathrm{mM}$ EDTA, pH 8.0), stored overnight at $-80^{\circ} \mathrm{C}$, then thawed on ice water. Cells were lysed with a French press. After centrifugation to collect cell debris, the supernatant was incubated with an amylose bead slurry (New England Biolabs) and washed several times with column buffer. The MBP-ENOD8 protein was eluted from the amylose beads with column buffer supplemented with $10 \mathrm{mM}$ maltose. After centrifugation, the supernatant was collected and concentrated by ultrafiltration with Ultrafree centrifugal filter units (Millipore, Billerica, MA, U.S.A.). Concentration of the purified recombinant MBP-ENOD8 protein was evaluated by Bradford assay with Coomassie protein assay reagent (Pierce, Rockford, IL, U.S.A.) and sodium dodecyl sulfate (SDS) polyacrylamide gel electrophoresis.

\section{MBP-ENOD8 polyclonal antiserum.}

Antisera were generated by immunizing rabbits with the purified MBP-ENOD8 fusion protein (Bio-synthesis, Inc., Lewisville, TX, U.S.A.). Preimmune serum was collected from each rabbit prior to immunization. Immunoblot analysis showed that the MBP-ENOD8 antiserum had the same specificity toward the ENOD8 protein from nodule-soluble extract, as the anti-ENOD8 oligopeptide antiserum previously tested (Dickstein et al. 2002).

\section{Affinity-purified anti-ENOD8 oligopeptide antibody.}

The anti-ENOD8 oligopeptide antisera (Dickstein et al. 2002) was incubated in a SulfoLink affinity chromatography column (Pierce), whose beads had been conjugated with the ENOD8 peptide, CKNPSTRITWDGTHYTEAA (SynPep, Dublin, CA, U.S.A.). The ENOD8 antibodies were eluted from the column by $0.2 \mathrm{M}$ glycine, $\mathrm{pH}$ 2.0. ENOD8 antibody fractions were collected directly in microcentrifuge tubes containing $1 \mathrm{M}$ Tris- $\mathrm{HCl}, \mathrm{pH}$ 9.2. The activity of the affinity-purified ENOD8 antibody fraction was validated by Western analysis.

\section{Immunomicroscopy.}

Mature pink nodules were collected from M. truncatula grown in aeroponics chambers. Nodules were vacuum infiltrated seven times, $30 \mathrm{~s}$ each with $0.5 \%$ (vol/vol) formaldehyde (Electron Microscopy Sciences, Hatfield, PA, U.S.A.) in phosphatebuffered saline (PBS; $137 \mathrm{mM} \mathrm{NaCl}, 10 \mathrm{mM}$ sodium phosphate, and $2.7 \mathrm{mM} \mathrm{KCl}$ ), $\mathrm{pH} 7.0$. After $20 \mathrm{~min}$ at RT, nodules were rinsed six times for $10 \mathrm{~min}$ in PBS, $\mathrm{pH}$ 7.0. Nodules were transferred to ice-cold $100 \%$ methanol and agitated overnight at $4{ }^{\circ} \mathrm{C}$. Nodules were rinsed in PBS, $\mathrm{pH} 7.0$, six times for 10 min each and were embedded in 6\% (wt/vol) low-melting-point agarose in PBS, pH 7.0. Tissues were sectioned with a Vibratome 1000 classic (Vibratome, St. Louis) mounted with a single-edge razor blade. Then, 50- $\mu \mathrm{m}$ sections were collected affixed on slides, which had been spotted with a drop of poly-L-lysine (SigmaAldrich, St. Louis) surrounded by a thin water-repellent film. All incubations for immunostaining were carried in 50- $\mu$ l volumes at RT in humidity chambers. Sections were incubated for $1 \mathrm{~h}$ in blocking buffer (3\% [wt/vol] bovine serum albumin [BSA], 5\% [vol/vol] normal goat serum [NGS], 0.1\% [vol/vol] Tween 20, PBS $\mathrm{pH}$ 7.0), then incubated for $1 \mathrm{~h}$ with a 1:100 dilution of the affinity-purified anti-ENOD8 oligopeptide antibody. In some experiments, the anti-ENOD8 oligopeptide antibody was coincubated with a 1:100 dilution of anti-histone $\mathrm{H} 1$ antibody (Upstate, Lake Placid, NY, U.S.A.). Sections were rinsed twice with blocking buffer and subsequently incubated with 1:500 dilution of secondary antibodies (Jackson ImmunoResearch Laboratories, West Grove, PA, U.S.A.) for $1 \mathrm{~h}$ : tetramethyl rhodamine isothiocyanate (TRITC)-conjugated goat anti-mouse $(\mathrm{H}+\mathrm{L})$, Cy5-conjugated goat anti-rabbit $(\mathrm{H}+\mathrm{L})$. Sections were rinsed twice with blocking buffer and stained for 15 min with $5 \mu \mathrm{M}$ SYTO13 (Invitrogen) in blocking buffer. Sections were washed twice for $5 \mathrm{~min}$ in blocking buffer. Sections were covered by a drop of anti-photobleaching media, ProLong Gold antifade reagent (Invitrogen) before laying a coverslip on them. Confocal images were acquired with a Perkin-Elmer UltraVIEW ERS spinning disk confocal microscope connected to a Zeiss Axiovert 200M (Carl Zeiss, Oberkochen, Germany), with $488 \mathrm{~nm}$ (SYTO13), $568 \mathrm{~nm}$ (TRITC), and $640 \mathrm{~nm}$ (Cy5) laser lines. Observations were made using a $\times 20($ NA 0.75$)$ or $\times 100$ (NA 1.4) objective lenses. Images were acquired as $\mathrm{z}$-stacks using the software developed by Perkin-Elmer provided with the Ultraview ERS. Data then was processed with ImageJ from NIH.

\section{Preparation of symbiosome fractions and immunoblot analysis.}

Symbiosome membrane, symbiosome space, and bacteroid protein fractions were purified as described previously (Catalano et al. 2004). Protein concentrations were determined using the Bio-Rad DC protein assay according to the manufacturer's instructions (Bio-Rad Laboratories, Hercules, CA, U.S.A.).

Symbiosome membrane, symbiosome space, and bacteroid protein fractions were resolved on SDS gels for immunoblot analyses as described (Catalano et al. 2004, 2007). Proteins were transferred to $0.45-\mu \mathrm{m}$ nitrocellulose membrane using a semidry electrophoretic transfer cell from Bio-Rad according to manufacturer's instructions (Bio-Rad Laboratories). The blot to be probed with ENOD8 antisera was blocked in $10 \mathrm{ml}$ of $1 \times$ Trisbuffered saline (TBS), pH 7.4, 2\% (wt/vol) BSA, 1\% (wt/vol) NGS, and $0.05 \%$ (vol/vol) Tween 20 at RT for $1 \mathrm{~h}$. The blot then was incubated in $10 \mathrm{ml}$ of block containing 1:5000 ENOD8 antisera for $2 \mathrm{~h}$ at RT followed by rinsing the blot five times in 10 $\mathrm{ml}$ of TBS-Tween (TBST) for $5 \mathrm{~min}$. The blot was incubated in $10 \mathrm{ml}$ of block containing 1:10,000 goat anti-rabbit immunoglobulin-G secondary antibody conjugated to horseradish peroxidase (Sigma-Aldrich) for $1 \mathrm{~h}$ at RT. Finally, the blot was rinsed four times in $10 \mathrm{ml}$ of TBST for $5 \mathrm{~min}$ and once in $10 \mathrm{ml}$ of TBS for $5 \mathrm{~min}$. Protein signal was detected using enhanced chemiluminescence. Nodulin-26 and dinitrogenase reductase Western blots were performed as described previously (Catalano et al. 2004; Guenther et al. 2003).

\section{ACKNOWLEDGMENTS}

We thank E. Blancaflor for suggestions on tissue fixation and antigen recovery; K. Luby-Phelps for help with confocal microscopy and use of the Live Cell Imaging Core at University of Texas Southwestern; K. 
VandenBosch for help with attempts at immunoelectron microscopy; A Wang and J. Park for help with the pMtENOD8-gusA construct; and S. Banker, B. Blackmon, and B. Huskinson for help characterizing the antiENOD 8 and anti-MBP-ENOD 8 antisera. This project was partially supported by United States Department of Agriculture Cooperative State Research, Education and Extension Service National Research Initiative Nitrogen Fixation Program grants 99-35305-8574, 99-35305-8693 to R. Dickstein and Plant Biochemistry Program grant 2005-35318-16215 to D. J. Sherrier.

\section{LITERATURE CITED}

Akoh, C. C., Lee, G. C., Liaw, Y. C., Huang, T. H., and Shaw, J. F. 2004 GDSL family of serine esterases/lipases. Prog. Lipid Res. 43:534552

Bertinetti, C., and Ugalde, R. A. 1996. Studies on the response of carrot cells to a Sclerotinia sclerotiorum elicitor: induction of the expression of an extracellular glycoprotein mRNA. Mol. Plant-Microbe Interact. 9:658-663.

Boisson-Dernier, A., Chabaud, M., Garcia, F., Becard, G., Rosenberg, C., and Barker, D. G. 2001. Agrobacterium rhizogenes-transformed roots of Medicago truncatula for the study of nitrogen-fixing and endomycorrhizal symbiotic associations. Mol. Plant-Microbe Interact. 14:695-700.

Brewin, N. J. 1991. Development of the legume root nodule. Annu. Rev. Cell Biol. 7:191-226.

Brewin, N. J. 2004. Plant cell wall remodelling in the Rhizobium-legume symbiosis. Crit. Rev. Plant Sci. 23:293-316.

Catalano, C., Lane, W. S., and Sherrier, D. J. 2004. Biochemical characterization of symbiosome membrane proteins from Medicago truncatula root nodules. Electrophoresis 25:519-531.

Catalano, C. M., Czymmek, K. J., Gann, J. G., and Sherrier, D. J. 2007. Medicago truncatula syntaxin SYP132 defines the symbiosome membrane and infection droplet membrane in root nodules. Planta. 225:541550.

Dahiya, P., Kardailsky, I. V., and Brewin, N. J. 1997. 1mmunolocalization of PsNLEC-1 I a lectin-like Glycoprotein expressed in developing pea nodules. Physiol. Plant 115:1431-1442.

Dickstein, R., Prusty, R., Peng, T., Ngo, W., and Smith, M. E. 1993. ENOD8, a novel early nodule-specific gene, is expressed in empty alfalfa nodules. Mol. Plant-Microbe Interact. 6:715-721.

Dickstein, R., Hu, X., Yang, J., Ba, L., Coque, L., Kim, D.-J., Cook, D. R., Yeung, A. T. 2002. Differential expression of tandemly duplicated Enod8 genes in Medicago. Plant Sci. 163:333-343.

Gage, D. J. 2004. Infection and invasion of roots by symbiotic, nitrogenfixing rhizobia during nodulation of temperate legumes. Microbiol. Mol. Biol. Rev. 68:280-300.

Guenther, J. F., Chanmanivone, N., Galetovic, M. P., Wallace, I. S., Cobb, J. A., and Roberts, D. M. 2003. Phosphorylation of soybean nodulin 26 on serine 262 enhances water permeability and is regulated developmentally and by osmotic signals. Plant Cell 15:981-991.

Haynes, J. G., Cyzmmek, K. J., Carlson, C. A., Veereshlingam, H., Dickstein, R., and Sherrier, D. J. 2004. A novel method for rapid analysis of legume root nodule development using confocal microscopy. New Phytol. 163:661-668.

Hirsch, A. M. 1992. Developmental biology of legume nodulation. New Phytol. 122:211-237.

Jones, K. M., Kobayashi, H., Davies, B. W., Taga, M. E., and Walker, G. C. 2007. How rhizobial symbionts invade plants: the SinorhizobiumMedicago model. Nat. Rev. Microbiol. 5:619-633.

Journet, E.-P., Pichon, M., Dedieu, A., de Billy, F., Truchet, G., and Barker, D. G. 1994. Rhizobium meliloti Nod factors elicit cell-specific transcription of the ENOD12 gene in transgenic alfalfa. Plant J. 6:241-249.

Journet, E. P., El-Gachtouli, N., Vernoud, B., de Billy, F., Pichon, M.,
Dedieu, A., Arnould, C., Morandi, D., Barker, D. G., and GianinazziPearson, V. 2001. Medicago truncatula ENOD11: a novel RPRP-encoding early nodulin gene expressed during mycorrhization in arbusculecontaining cells. Mo. Plant-Microbe Interact. 14:737-748.

Kandzia, R., Grimm, R., Eckerskorn, C., Lindemann, P., and Luckner, M. 1998. Purification and characterization of lanatoside 15'-O-acetylesterase from Digitalis lanata Ehrh. Planta 204:383-389.

Kannenberg, E. L., and Carlson, R. W. 2001. Lipid A and O-chain modifications cause Rhizobium lipopolysaccharides to become hydrophobic during bacteroid development. Mol. Microbiol. 39:379-391.

Kardailsky, I. V., Sherrier, D. J., and Brewin, N. J. 1996. Identification of a new pea gene, PsNlec1, encoding a lectin-like glycoprotein isolated from the symbiosomes of root nodules. Plant Physiol. 111:49-60.

Liu, J., Miller, S. S., Graham, M., Bucciarelli, B., Catalano, C., Sherrier, D. J., Samac, D. A., Ivashuta, S., Fedorova, M., Matsumoto, P., Gantt, J. S., and Vance, C. P. 2006. Recruitment of novel calcium binding proteins for root nodule symbiosis in Medicago truncatula. Plant Physiol. 141:167-177.

Lullien, V., Barker, D. G., de Lajudie, P., and Huguet, T. 1987. Plant gene expression in effective and ineffective root nodules of alfalfa (Medicago sativa). Plant Mol. Biol. 9:469-478.

Mylona, P., Pawlowski, K., and Bisseling, T. 1995. Symbiotic nitrogen fixation. Plant Cell 7:869-885.

Panter, S., Thomson, R., de Bruxelles, G., Laver, D., Trevaskis, B., and Udvardi, M. 2000. Identification with proteomics of novel proteins associated with the peribacteroid membrane of soybean root nodules. Mol. Plant-Microbe Interact. 13:325-333.

Pringle, D., and Dickstein, R. 2004. Purification of ENOD8 proteins from Medicago sativa root nodules and their characterization as esterases. Plant Physiol. Biochem. 24:73-79.

Saalbach, G., Erik, P., and Wienkoop, S. 2002. Characterisation by proteomics of peribacteroid space and peribacteroid membrane preparations from pea (Pisum sativum) symbiosomes. Proteomics 2:325-337.

Sherrier, D. J., Taylor, G. S., Silverstein, K. A. T., Gonzales, M. B., and VandenBosch, K. 2005. Accumulation of extracellular proteins bearing unique proline-rich motifs in intercellular spaces of the legume nodule parenchyma. Protoplasma 225:43-55.

Tanaka, R., Ikeda, M., Funatsuki, K., Yukioka, H., Hashimoto, Y., Fujimoto, S., Takata, M., Katoh, K., and Konno, H. 2002. Molecular cloning and cytochemical analysis of exopolygalacturonase from carrot. Planta 215:735-744

Udvardi, M. K., and Day, D. A. 1997. Metabolite transport across symbiotic membranes of legume nodules. Annu. Rev. Plant Physiol. Plant Mol. Biol. 48:493-523

Upton, C., and Buckley, J. T. 1995. A new family of lipolytic enzymes? Trends Biochem. Sci. 20:178-179.

van Engelen, F. A., de Jong, A. J., Meijer, E. A., Kuil, C. W., Meyboom, J. K., Dirkse, W. G., Booij, H., Hartog, M. V., Vandekerckhove, J., de Vries, S. C., and van Kammen, A. 1995. Purification, immunological characterization and cDNA cloning of a $47 \mathrm{kDa}$ glycoprotein secreted by carrot suspension cells. Plant Mol. Biol. 27:901-910.

Vasse, J., de Billy, F., Camut, S., and Truchet, G. 1990. Correlation between ultrastructural differentiation of bacteroids and nitrogen fixation in alfalfa nodules. J. Bacteriol. 172:4295-4306.

Veereshlingam, H., Haynes, J. G., Sherrier, D. J., Penmetsa, R. V., Cook, D. R., and Dickstein, R. 2004. nip, A symbiotic Medicago truncatula mutant that forms root nodules with aberrant infection threads and plant defense-like response. Plant Physiol. 136:3692-3702.

Vincent, J. L., and Brewin, N. J. 2000. Immunolocalization of a cysteine protease in vacuoles, vesicles, and symbiosomes of pea nodule cells. Plant Physiol. 123:521-530.

Wienkoop, S., and Saalbach, G. 2003. Proteome analysis. Novel proteins identified at the peribacteroid membrane from Lotus japonicus root nodules. Plant Physiol. 131:1080-1090. 